\title{
Utilização do lúdico por meio de dominó para a aprendizagem de alcanos por alunos de Curso Técnico em Química
}

Evandro Falass da Silva evandrofalass@gmail.com Instituto Federal do Paraná (IFPR), Paranavaí, Paraná, Brasi

Gleison Leandro Santos Sousa gleisonnego1@gmail.com Instituto Federal do Paraná (IFPR), Paranavaí, Paraná, Brasil

Wagner Neves Junior wagner neves18@hotmail.com Paranavaí, Paraná, Brasil

Gláucio Testa

glaucio.testa@ifpredu.br nstituto Federal do Paraná (IFPR), Paranavaí, Paraná, Brasil

Tatiana Colombo Pimentel tatiana.pimentel@ifpr.edu.br do Paraná (IFPR), Paranavaí, Paraná, Brasil

\section{RESUMO}

Os jogos são tradicionais e presentes na vida humana há tempos, sendo capazes de colaborar com a concentração e motivar quem está jogando. Dessa forma, surge a ideia de ensinar conteúdos escolares por meio de jogos. No campo da Química não tem sido diferente, pois existem enormes dificuldades para ter a atenção e dedicação dos alunos. A nomenclatura de alcanos é um conteúdo fundamental para a compreensão das nomenclaturas das funções orgânicas, tais como: aldeídos, ácidos carboxílicos, cetonas, ésteres etc. $\mathrm{O}$ objetivo do presente trabalho foi avaliar o efeito da utilização de um jogo de dominó na aprendizagem da nomenclatura de alcanos. $O$ jogo foi desenvolvido e aplicado em uma turma do primeiro ano do Curso Técnico em Química de um colégio da cidade de Paranavaí, Paraná. O experimento consistiu em uma retomada do conteúdo de hidrocarbonetos, aplicação de uma avaliação diagnóstica (5 questões com tempo de 20 minutos para responder), utilização do jogo e posterior aplicação de nova avaliação. A contabilização do rendimento dos estudantes foi feita atribuindo nota de 0 a 10 às avaliações e comparando-as. Os resultados indicaram que o jogo Dominó de Alcanos facilitou o aprendizado dos alunos, havendo melhoria na média da avaliação em $29 \%$, com nota inicial de 5,5 e final de 7,1. Conclui-se que o jogo Dominó de Alcanos se constituiu como uma ferramenta importante na melhoria do aprendizado dos alunos, sendo simples de se jogar e motivador. A ideia do jogo pode ser expandida para outros conteúdos.

PALAVRAS-CHAVE: Educação lúdica. Dominó. Química. Educação. Ensino de Química. 


\section{INTRODUÇÃO}

Há muito tempo se acreditava na aprendizagem do aluno por meio da repetição do conteúdo aplicado, e na prática de decorar o que se foi aplicado em sala de aula ou contido no livro didático. Dessa forma, alunos que não aprendessem eram considerados não dedicados ou que apresentavam muita dificuldade (CUNHA, 2012).

De acordo com os Parâmetros Curriculares Nacionais (BRASIL,1999) o ensino, não somente em Química, mas em todas as áreas, deve ter mais interações e diversão, sendo expresso de uma maneira mais dinâmica. Assim, se rompe o hábito do método tradicional de ensino e se desperta o interesse maior no aluno.

Alguns materiais ou métodos de ensino exteriores da sala de aula e dos livros didáticos podem facilitar o aprendizado do aluno. Isso pode ser observado quando o professor demonstra o conteúdo aplicado com objetos do dia a dia e da rotina de vida que o aluno apresenta, sendo utilizados, por exemplo, objetos como cordões, isopor, arames, bolas etc. (SOARES, 2004).

Outro método de ensino capaz de buscar atenção do aluno e facilitar sua capacidade de aprender o conteúdo aplicado pelo professor é a utilização de jogos ou atividades lúdicas. Estes são de extrema importância na vida do aluno, desenvolvendo um maior raciocínio e melhorando a atenção em sala de aula, aumentando também sua dedicação e interesse e motivando-os a buscar maior conhecimento (SOARES, 2004).

Segundo Soares (2008), o lúdico não é somente para melhoria de aprendizado para crianças e adolescentes, mas também para utilidade dos adultos e, com isso, essa prática ou método de ensino-aprendizagem deve ser mais valorizada. Para ele, o lúdico traz contribuições sociais e educativas, sendo assim todas as pessoas envolvidas com a educação estarão evoluindo em relação ao conhecimento e vivência em sociedade.

Os jogos sempre foram algo presente na vida das pessoas. Platão (427- 348 a. C) já relatava a grande importância de aprender brincando. Para os Romanos, os jogos eram utilizados para a formação de soldados e cidadãos (KISHIMOTO, 1996). Após a revolução Francesa surgiram as inovações pedagógicas e, a partir do século XX, Frobel propôs que os jogos fossem utilizados de uma maneira mais correta, com o controle e autonomia dos professores (ARCE, 2001).

As atividades lúdicas, além da diversão, têm a função de educar. Para que isso aconteça, é necessário aplicar os jogos de uma maneira equilibrada, entre diversão e ensino, pois, sem esse equilíbrio, o jogo não passará de um material didático sem interesse para os alunos (KISHIMOTO, 1996). As atividades lúdicas oferecem oportunidades de desenvolver o raciocínio, maior reflexão sobre as atitudes e decisões tomadas no jogo e, assim, aos poucos se aumenta o conhecimento por meio da memorização. Para Melo (2005), o lúdico é uma das mais importantes ferramentas de trabalho para o professor, quando utilizado da maneira correta e respeitosa, mantendo um clima agradável em sala de aula e, quando explorado da maneira certa, o aluno também recebe um novo ensino possibilitando o desenvolvimento social e pessoal. Dessa maneira, o jogo é de grandioso valor e importância no ensino e aprendizagem. 
Muito utilizados como método de ensino e aprendizagem nas disciplinas de matemática e ciências, os jogos também estão ganhando seu espaço em Química, utilizados também como um instrumento de motivação e desafio para os alunos do Ensino Médio e Técnico, deixando de ser atração muitas vezes apenas para alunos que estão nos primeiros anos de escolaridade (SOARES, 2004). Para o ensino de Química, exemplos do cotidiano quando aplicados com experiências em laboratórios ou aulas, de uma maneira simples e fácil de entender, são aulas mais proveitosas e com maior facilidade para entendimento do aluno sobre o conteúdo (BRASIL, 1999).

Ensinando Química, por meio de jogos, a partir dos erros dos alunos, o professor pode se aproveitar da situação para corrigir e assim explicar novamente o conteúdo, mostra ao aluno a maneira correta, sendo uma retomada dos conteúdos aplicados na aula, durante o momento de diversão. Com isso, o aluno estará aprendendo brincando, aumentando o conhecimento, sentindo prazer ao aprender e deixando de ver o erro como algo ruim, mas sim como uma oportunidade a mais de aprendizado.

O dominó é um jogo estratégico, que pode ser jogado por dois ou quatro jogadores. Esse jogo não possui regras oficiais universais.

A Química orgânica é o ramo da Química que estuda os compostos formados por carbonos, sendo uma de suas funções os hidrocarbonetos (compostos que possuem apenas carbonos e hidrogênios). Dentro dos hidrocarbonetos são encontrados os alcanos (compostos orgânicos formados por ligações simples), cadeias abertas e com fórmula $\mathrm{C}_{n} \mathrm{H}_{2 n+2}$. Para nomear os alcanos, é necessário seguir as regras estabelecidas pela IUPAC (União Internacional de Química Pura e Aplicada), com prefixos que indicam a quantidade de carbonos presentes na cadeia (POWELL; FRAVE, 2013)

Considerando o possível efeito das atividades lúdicas na aprendizagem de conteúdos de Química, o objetivo do presente trabalho foi avaliar o efeito da aplicação de um dominó na aprendizagem do conteúdo de nomenclatura de alcanos por alunos de Curso Técnico em Química.

\section{MATERIAL E MÉTODOS}

O jogo de dominó oficial apresenta 28 pedras, sendo que em sua face há pontos indicando valores numéricos de 0 a 6 . No presente trabalho, um jogo educativo foi confeccionado, sendo composto por 64 pedras, com uma maneira diferente de numeração, podendo ser jogado por até 9 jogadores (Figura 1). 
Figura 1 - Dominó de Alcanos

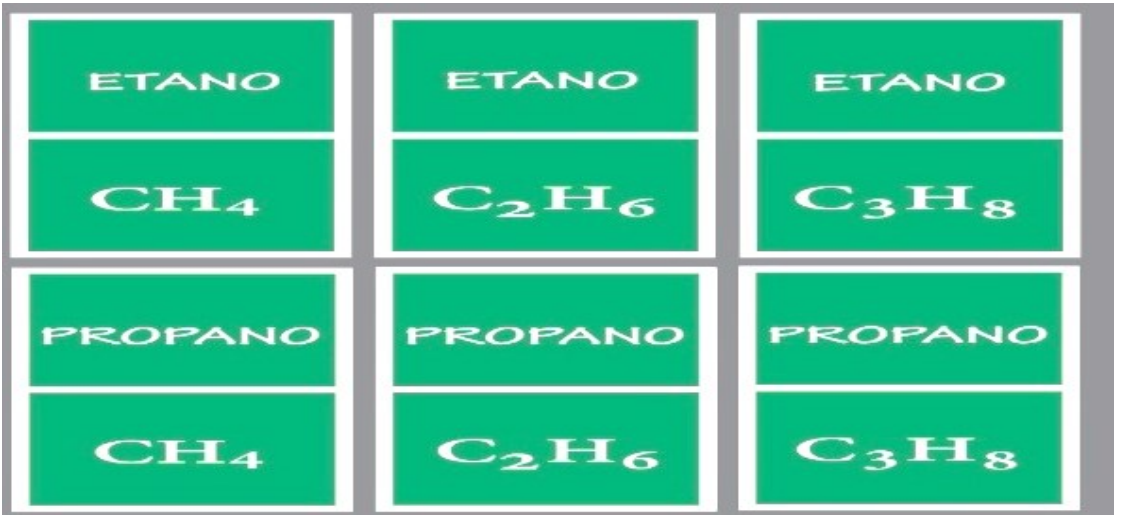

Fonte: Autoria própria (2017).

Para iniciar o jogo, o jogador que saísse com a maior peça (decano/C10H22) começava colocando-a na mesa. Em seguida, o jogador que estava ao seu lado em sentido horário dava sequência ao jogo. Cada jogador deveria tentar encaixar uma de suas pedras nas extremidades do jogo na mesa, lembrando que só era válido encaixar a pedra com a nomenclatura naquela que apresentava a cadeia orgânica correspondente ou vice-versa (Figura 2).

Figura 2 - Imagem das peças dispostas

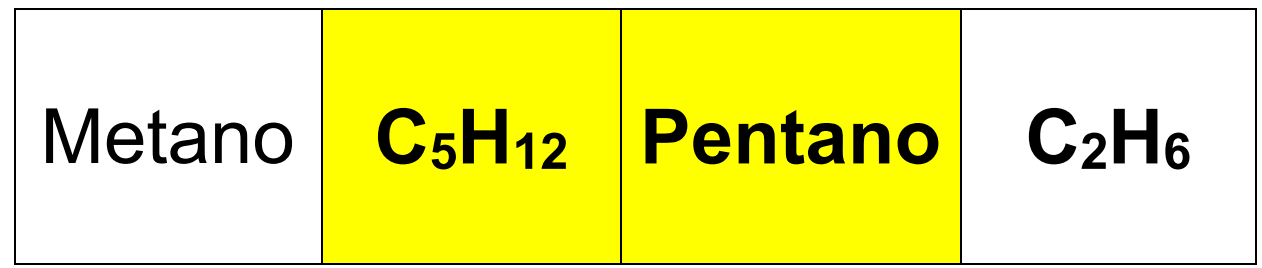

Fonte: Autoria própria (2017).

Quando o jogador conseguisse encaixar sua peça ele passaria a vez, ou, caso não conseguisse, ele deveria retirar mais uma peça do montante restante. Se não houvesse mais peças no montante, terminava sua participação na rodada. 0 jogo era finalizado quando algum jogador ficasse sem peças ou quando não era mais possível encaixar peças. No último caso, o ganhador seria o jogador que apresentasse o menor número de carbonos em mãos (Figura 3).

Figura 3 - Exemplo de peças no final do jogo

\begin{tabular}{|c|c|c|c|c|}
\hline Metano & $\mathrm{C}_{10} \mathrm{H}_{22}$ & Etano & Heptano & Propano \\
\hline $\mathrm{CH}_{4}$ & Butano & $\mathrm{CH}_{4}$ & $\mathrm{C}_{8} \mathrm{H}_{18}$ & $\mathrm{C}_{3} \mathrm{H}_{8}$ \\
\hline Jogador 01 & \multicolumn{2}{|c|}{ Jogador 02} & \multicolumn{2}{|c|}{ Jogador 03} \\
\hline
\end{tabular}

Fonte: Autoria própria (2017). 
Na Figura 3, anteriormente apresentada, o jogador 1 tinha 2 carbonos, somando os carbonos da nomenclatura (metano) e a fórmula molecular $(\mathrm{CH} 4)$, o jogador 2 tinha 17 carbonos e o jogador 3 tem 21 carbonos. Então, nessa partida, ao final do jogo, o jogador 1 foi o ganhador, pois estava com apenas dois carbonos em mãos.

O custo de preparação do jogo dominó de alcanos está apresentado no Quadro 1.

Quadro 1 - Custo de produção das peças

\begin{tabular}{ccc}
\hline Material & Quantidade & Custo \\
\hline Placas de EVA & 2 & $\mathrm{R} \$ 10,00$ \\
\hline Trabalho serigráfico & 1 & $\mathrm{R} \$ 30,00$ \\
\hline Custo Total (64 peças) & & $\mathrm{R} \$ 40,00$ \\
\hline
\end{tabular}

Fonte: Autoria própria (2017).

O jogo foi aplicado durante as aulas de Química orgânica e Química inorgânica no Colégio Enira de Moraes Ribeiro E. F. M. P., na cidade de Paranavaí, no dia 8 de maio de 2017, no período noturno, em uma turma de primeiro ano de Curso Técnico em Química. Antes da aplicação do jogo, em sala de aula, realizou-se uma breve introdução sobre o conteúdo de hidrocarbonetos, abordando as diferenciações de alcanos, alcenos e alcinos, assim como as diversas formas de representação, como a fórmula molecular, fórmula estrutural, fórmula condensada e fórmula de linhas. Após a retomada de conteúdo, aplicou-se uma avaliação diagnóstica com cinco exercícios de alcanos (Figura 4), com a finalidade de avaliar o nível de conhecimento e o desempenho dos alunos. A avaliação foi aplicada em 20 minutos. Depois que todos terminaram a avaliação, a turma foi dividida em três grupos sendo, dois deles com nove participantes e um com oito.

O jogo Dominó de Alcanos foi aplicado em duas aulas, nas quais, no início, foi trabalhada a jogabilidade, e nesse momento, todos se ajudavam. Após algumas partidas, ao perceber que o jogo fluía de forma mais espontânea, foi inibido o auxílio do professor e dos responsáveis em aplicar o jogo, bem como foi solicitado que os participantes da atividade se concentrassem nas estruturas e nas formas moleculares.

Figura-4 - Avaliação diagnóstica (continua na próxima página)

\section{Avaliação Diagnóstica}

1. De acordo com seus conhecimentos, determine a fórmula molecular dos alcanos abaixo:

a) Octano e) Propano.

b) Pentano f) Heptano

c) Butano

d) Metano;

2. Determine o nome do composto abaixo:

$$
\mathrm{H}_{3} \mathrm{C}-\mathrm{CH}_{2}-\mathrm{CH}_{2}-\mathrm{CH}_{2}-\mathrm{CH}_{3}
$$

3. (FAFI/BH-MG) A nomenclatura da seguinte estrutura é:

$$
\mathrm{H}_{3} \mathrm{C}-\mathrm{CH}_{2}-\mathrm{CH}_{2}-\mathrm{CH}_{2}-\mathrm{C}-\mathrm{C}-\stackrel{\mathrm{CH}_{2}-\mathrm{CH}_{3}}{\mathrm{CH}_{3} \mathrm{CH}_{2}-\mathrm{CH}_{2}-\mathrm{CH}_{3}}
$$


5,5,6-trimetil-6-n-propiloctano.

5,5-dimetil-6,6-metil-n-propiloctano.

6-etil-5,5,6-trimetilnonano.

4-etil-4,5,5-trimetilnonano.

4. De acordo com a fórmula molecular, forneça a nomenclatura para os seguintes alcanos:

a) $\mathrm{C}_{5} \mathrm{H}_{12}$ :

b) $\mathrm{C}_{4} \mathrm{H}_{10}$ :

c) $\mathrm{C}_{3} \mathrm{H}_{8}$ :

d) $\mathrm{C}_{6} \mathrm{H}_{14}$ :

e) $\mathrm{C}_{7} \mathrm{H}_{16}$ :

f) $\mathrm{C}_{10} \mathrm{H}_{22}$ :

5. Relacione as colunas abaixo identificando cada formula molecular com o seu nome correspondente.
- a) $\mathrm{C}_{7} \mathrm{H}_{16}$ :
b) $\mathrm{C}_{5} \mathrm{H}_{12}$ :
c) $\mathrm{C}_{4} \mathrm{H}_{10}$ :
( ) Propano
( ) Decano
d) $\mathrm{C}_{3} \mathrm{H}_{8}$ :
( ) Etano
e) $\mathrm{C}_{2} \mathrm{H}_{6}$ :
( ) Heptano
f) $\mathrm{C}_{10} \mathrm{H}_{22}$ :
( ) Pentano
( ) Butano

Fonte: Autoria própria (2017).

Após aplicado o jogo, os alunos voltaram para a sala de aula e foi realizada a aplicação de uma nova avaliação.

As avaliações foram corrigidas pelo método de nota, com valores de 0 a 10. Esse tipo de avaliação foi selecionado levando em conta os métodos avaliativos aos quais a turma estava habituada. Para validação e certificação da metodologia utilizada, foi feita análise dos resultados obtidos com as avaliações aplicadas, a avaliação diagnóstica e a avaliação pós-jogo, comparando o desempenho dos alunos.

\section{RESULTADOS E DISCUSSÕES}

As notas obtidas pelos 26 alunos estão apresentadas no Quadro 2.

Quadro 2 - Notas obtidas pelos alunos nas avaliações diagnóstica e pós-jogo

\begin{tabular}{ccc}
\hline Aluno & Avaliação 1 & Avaliação 2 \\
\hline 1 & 0,0 & 0,0 \\
\hline 2 & 8,0 & 9,6 \\
\hline 3 & 0,0 & 8,0 \\
\hline 4 & 10,0 & 8,0 \\
\hline 5 & 0,0 & 5,3 \\
\hline 6 & 6,0 & 7,6 \\
\hline 7 & 6,0 & 6,0 \\
\hline 8 & 8,0 & 10,0 \\
\hline 9 & 5,6 & 9,6 \\
\hline 10 & 6,0 & 8,0 \\
\hline 11 & 3,0 & 3,0 \\
\hline 12 & 9,6 & 10,0 \\
\hline 13 & 4,0 & 7,0 \\
\hline
\end{tabular}




\begin{tabular}{ccc}
\hline Aluno & Avaliação & Avaliação 2 \\
\hline 14 & 10,0 & 10,0 \\
\hline 15 & 0,0 & 0,0 \\
\hline 16 & 10,0 & 10,0 \\
\hline 17 & 10,0 & 10,0 \\
\hline 18 & 5,0 & 10,0 \\
\hline 19 & 10,0 & 9,6 \\
\hline 20 & 7,0 & 10,0 \\
\hline 21 & 0,0 & 0,0 \\
\hline 22 & 8,0 & 8,0 \\
\hline 23 & 7,6 & 8,0 \\
\hline 24 & 6,0 & 9,0 \\
\hline 25 & 7,6 & 8,0 \\
\hline 26 & 2,0 & 8,0 \\
\hline
\end{tabular}

Fonte: Autoria própria (2017).

Foi observado que a turma do primeiro ano do Curso Técnico em Química não apresentou desempenho homogêneo na avaliação diagnóstica, pois $19 \%$ dos alunos obtiveram notas extremamente baixas (0), enquanto $23 \%$ tiveram desempenho considerado ótimo (entre 9 e 10). Considerando como satisfatório o acerto de $70 \%$ das questões, é possível observar que a maioria (54\%) dos alunos não foi capaz de atingir esse patamar na avaliação diagnóstica inicial, conforme representado Figura 5. 
Figura 5 - Rendimento dos Alunos

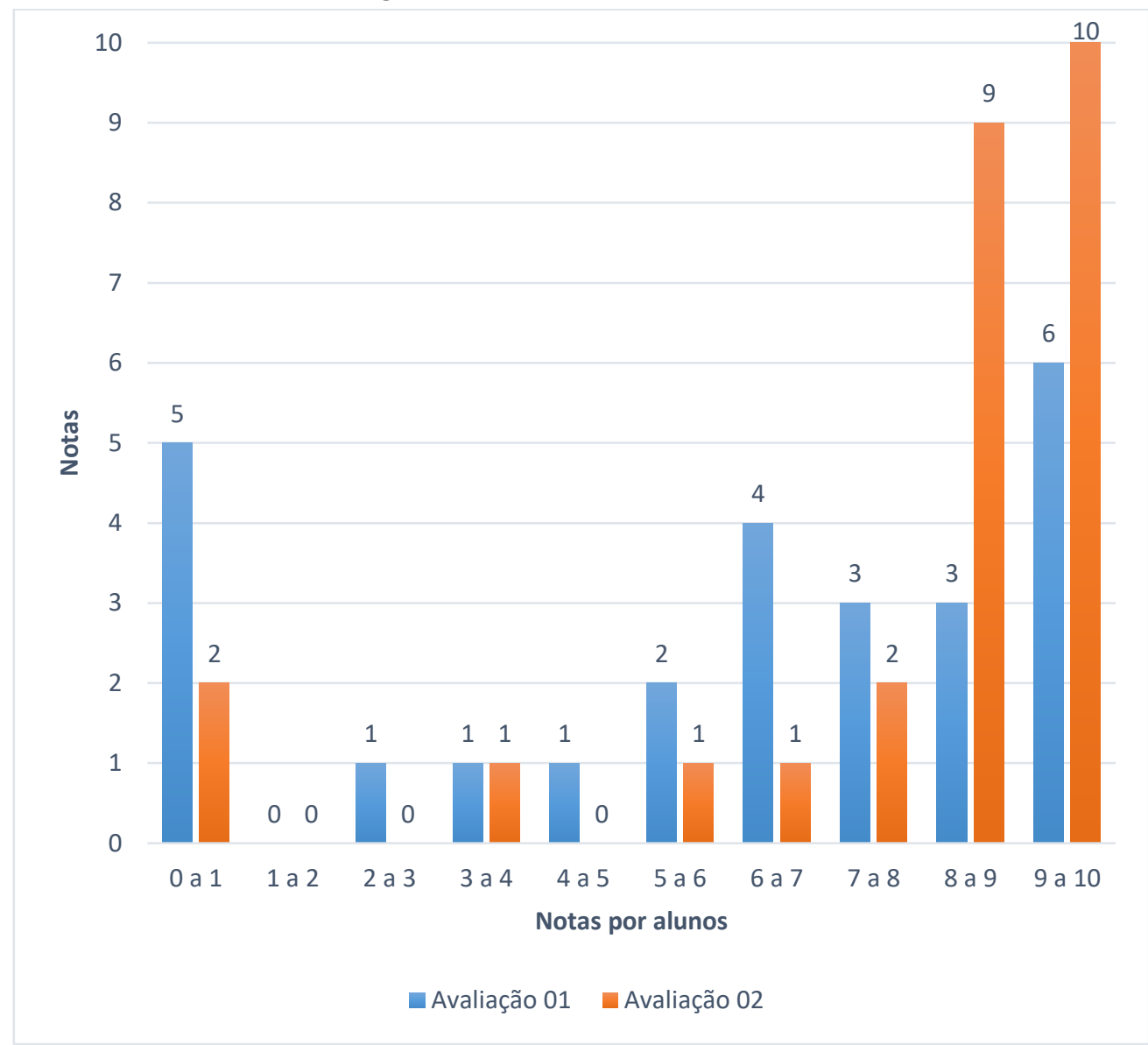

Fonte: Autoria própria (2017).

Durante a aplicação do jogo, foi observado que muitos dos erros cometidos pelos alunos eram simples, como a confusão entre $\mathrm{CH}_{4}$ (metano) e $\mathrm{C}_{4} \mathrm{H}_{10}$ (Butano). Percebeu-se, ainda, que a nomenclatura também estava bastante confusa para quase todos e os diversos tipos de representação das moléculas também atrapalhavam a compreensão do conteúdo abordado no jogo.

Enquanto a metodologia proposta estava sendo aplicada, muitos alunos aproveitaram para tirar dúvidas, pedindo explicações, e no decorrer da atividade, além da diversão generalizada, a sensação era de um trabalho bem feito, pois o conteúdo começou a fluir naturalmente. Em determinado momento, os próprios alunos começavam a se auto corrigir.

Com os resultados da segunda avaliação, comprovou-se o bom aproveitamento da atividade, pois na primeira avaliação a média global da turma foi de 5,5, enquanto, após o desenvolvimento do jogo, a média da turma subiu para 7,1 , tendo uma melhoria de $29 \%$ no aproveitamento.

Analisando os dados obtidos com a avaliação diagnóstica, 9 alunos tiveram aproveitamento inferior a $60 \%$. Destes, $55 \%$ tiveram melhora significativa no desempenho, inclusive alunos que não conseguiram responder de forma adequada nenhuma das questões atingiram $80 \%$ de aproveitamento após a utilização do jogo (aluno 3, Quadro 2). 
A turma era formada por 26 alunos, sendo 8 mulheres e 18 homens. Comparandose as duas avaliações, observou-se que ambos tiveram média semelhante ( $p>0.05)$, pois, na primeira avaliação os homens tiveram média de 5,95 e as mulheres de 5,25 e, na segunda avaliação, os homens tiveram média de 7,32 e as mulheres 7,61 (Figura 6). Os resultados indicam que a melhoria na aprendizagem proporcionada pelo jogo Dominó de Alcanos é independente do gênero dos estudantes.

Figura 6 - Nota média da avaliação separado por sexo

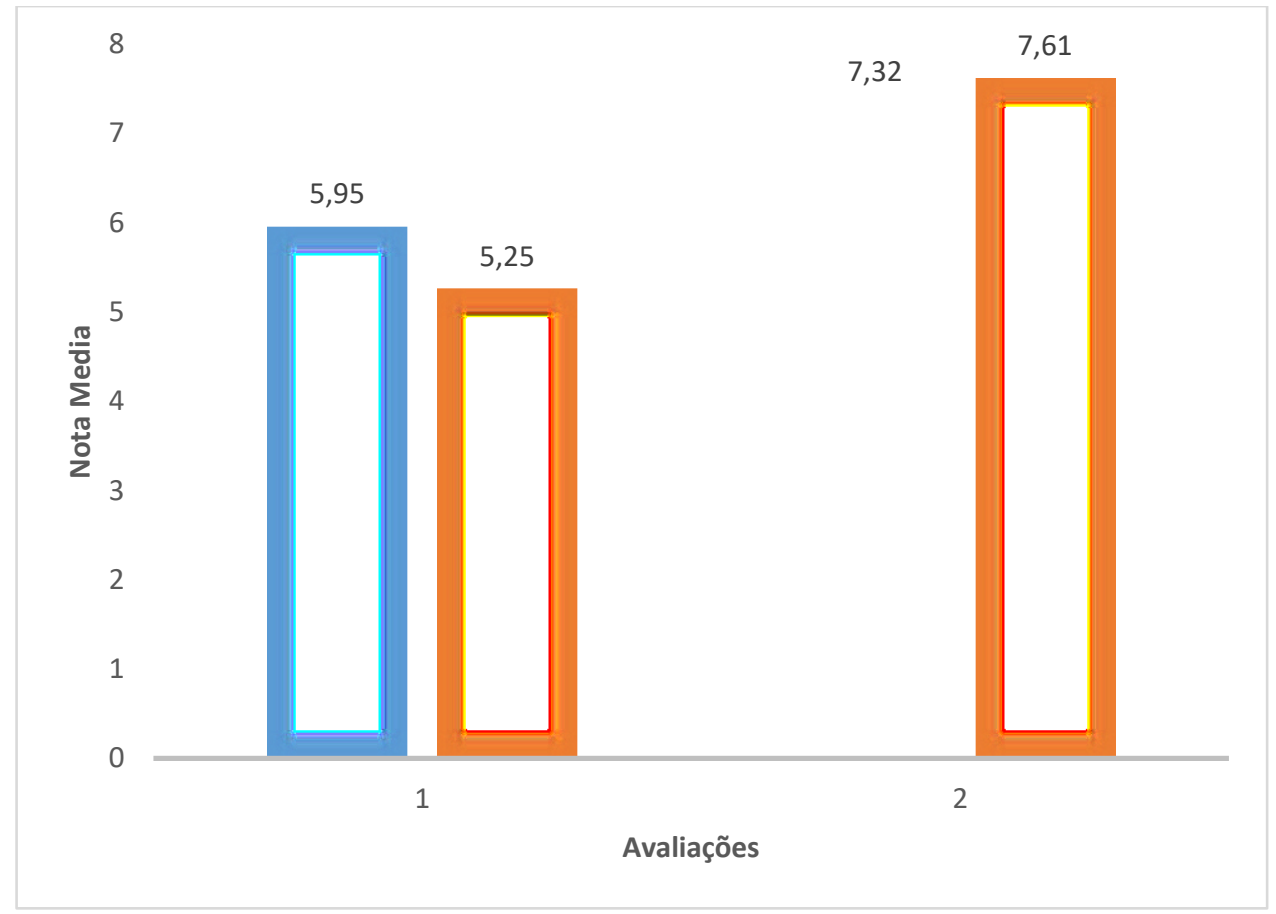

Fonte: Autoria própria (2017).

Também foi analisada a faixa etária dos alunos. Como se tratava de um curso técnico subsequente, os alunos tinham idade acima de 17 anos (Figura 7) e todos já haviam concluído o Ensino Médio, ou seja, o conteúdo abordado na proposta já havia sido ensinado aos alunos no passado. Em muitos casos, os alunos não frequentavam uma sala de aula há vários anos, como pode ser observado na Figura 8, o que também influenciou muito no aprendizado. 
Figura 7 - Faixa etária dos estudantes

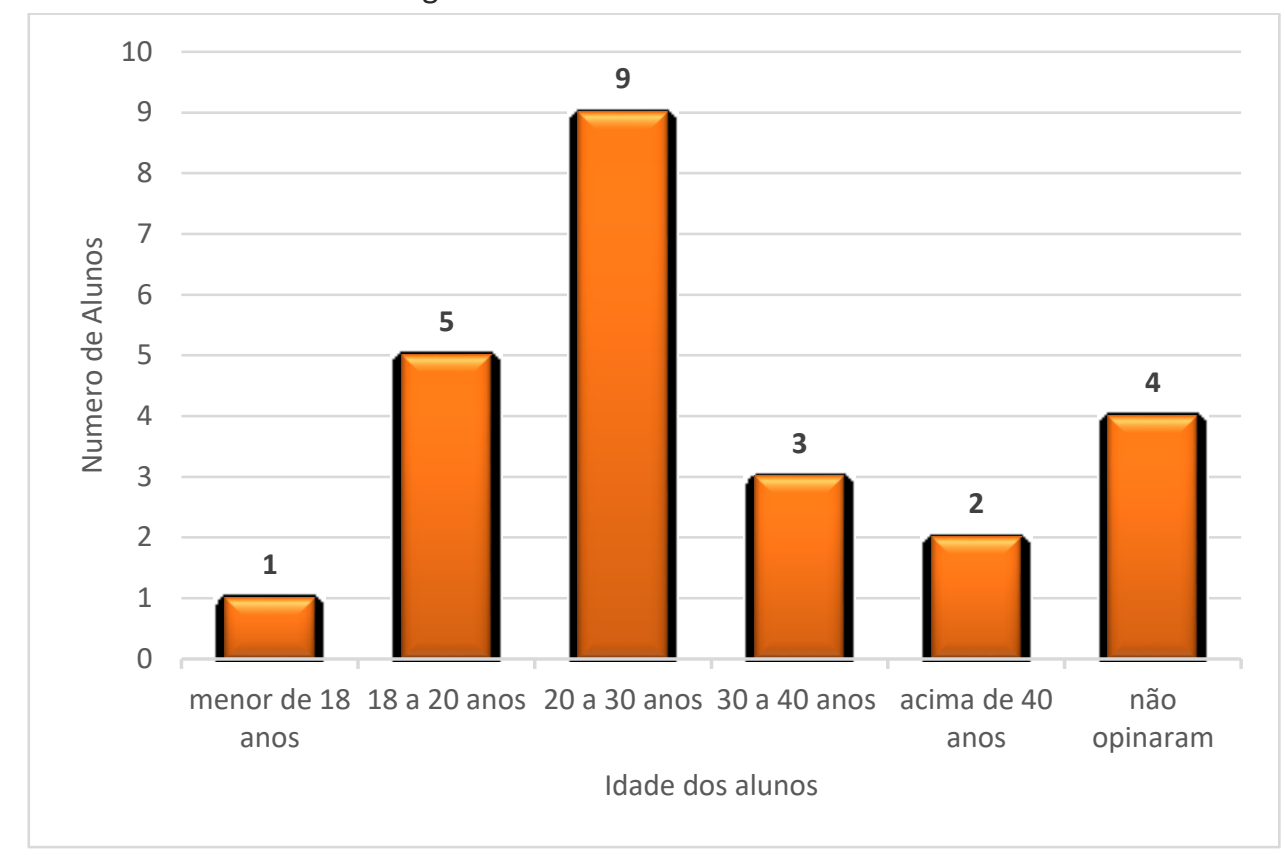

Fonte: Autoria própria (2017).

Figura 8 - Tempo de afastamento da escola dos alunos de Curso Técnico em Química

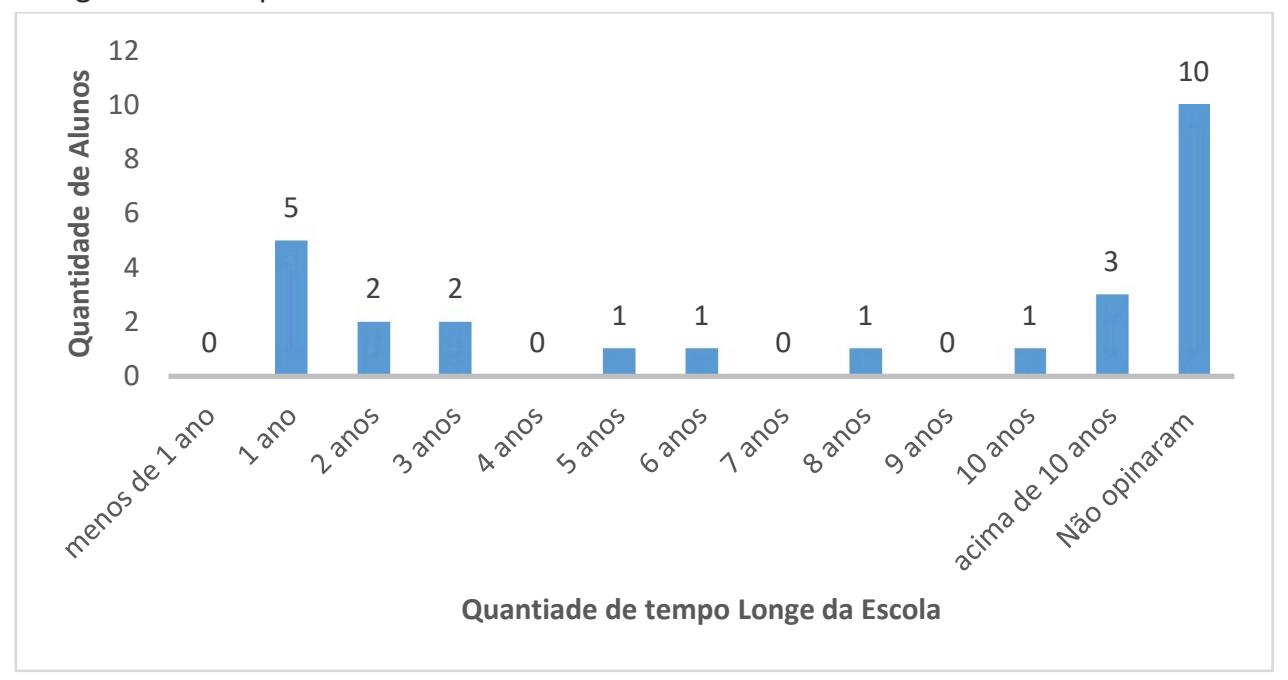

Fonte: Autoria própria (2017).

Outro fator influenciador analisado referente ao desempenho dos alunos foi que a maioria deles trabalha durante o dia, cerca de $53,85 \%$, enfrentando, em muitos casos, até uma hora de viagem de ônibus para estudarem no período noturno (Figura 9). 
Figura 9 - Tempo de trânsito dos alunos até a escola

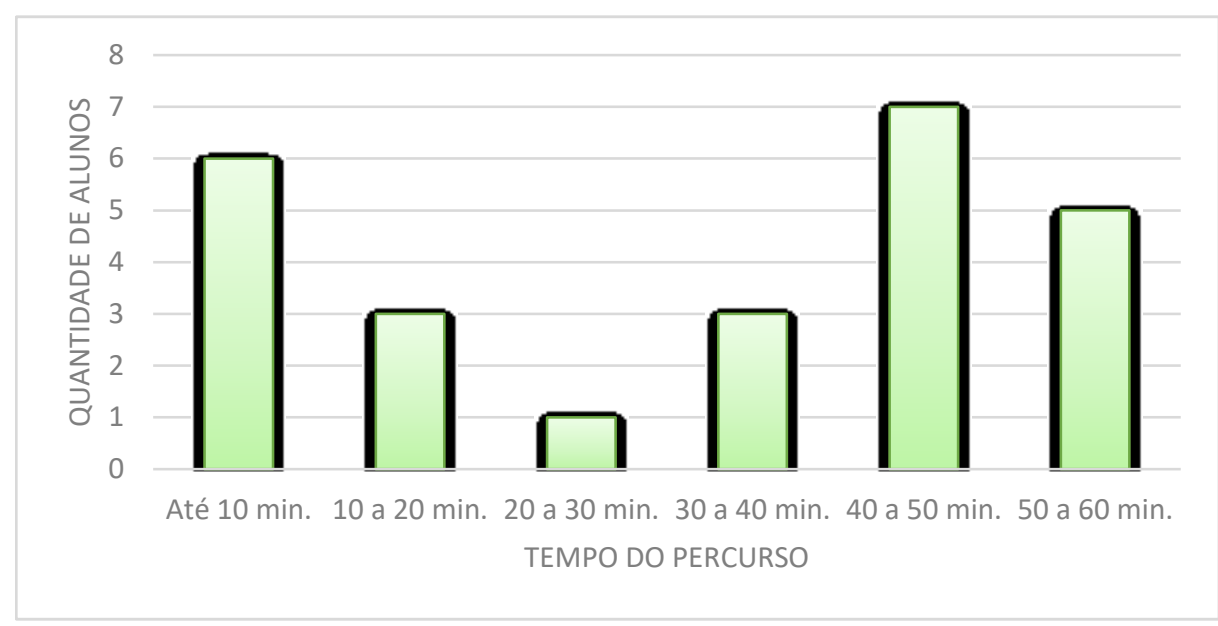

Fonte: Autoria própria (2017).

Praticamente mais da metade dos alunos, 54\%, mora em cidades vizinhas a Paranavaí, como pode ser observado no Quadro 3.

\begin{tabular}{|c|c|}
\hline Alunes & Recidência \\
\hline 1 & Paranavaí \\
\hline 2 & Terra Rica \\
\hline 3 & São João do Caiuá \\
\hline 4 & São João do Caiuá \\
\hline 5 & Paranavaí \\
\hline 6 & Terra Rica \\
\hline 7 & Paranavaí \\
\hline 8 & Paranavaí \\
\hline 9 & Tamboara \\
\hline 10 & Paranavaí \\
\hline 11 & Nova Londrina \\
\hline 12 & Nova Londrina \\
\hline 13 & Guairaça \\
\hline 14 & Paranavaí \\
\hline 15 & Nova Londrina \\
\hline 16 & São João do Caiuá \\
\hline 17 & Paranavaí \\
\hline 18 & Paranavaí \\
\hline 19 & Marilena \\
\hline 20 & Tamboara \\
\hline 21 & Paranavaí \\
\hline 22 & Rondon \\
\hline 23 & Paranavaí \\
\hline 24 & Nova Esperança \\
\hline 25 & Tamboara \\
\hline 26 & Paranavaí \\
\hline
\end{tabular}

Fonte: Autoria própria (2017).

Para esses alunos que moram em outra cidade, a aprendizagem fica ainda mais deficiente, uma vez que, para retornar para suas casas, alguns deles são liberados 
com até 30 minutos de antecedência para poder pegar a condução. Nesses casos, a saída mais cedo é um fator complicador do ensino, pois na última aula, que se inicia às $22 \mathrm{~h} 15 \mathrm{~min}$, o professor tem apenas 15 minutos para aplicar o conteúdo, já que, às $22 \mathrm{~h} 30 \mathrm{~min}$, alguns alunos começam a deixar a sala de aula. Outro fator complicador é que os alunos que permanecem em sala também acabam se prejudicando com a movimentação dos companheiros de sala, fato que gera uma desatenção, haja visto que a saída dos colegas é constante a partir das $22 \mathrm{~h} 30 \mathrm{~min}$, o que torna quase impossível trabalhar o conteúdo disciplinar na última aula.

Outro ponto observado em relação aos alunos que moram em outra cidade é que, além de terem que sair mais cedo na última aula, eles também chegam um pouco mais tarde na primeira aula. Isso acontece devido ao horário que as conduções chegam no colégio, pois o ônibus transporta alunos de várias instituições e, por isso, o motorista precisa percorrer praticamente toda a cidade. Dessa maneira, parte dos alunos dessa condução não consegue chegar no horário e, com isso, muitos são prejudicados.

Esses fatos são alguns dos motivos que tornam o resultado deste trabalho positivo e muito gratificante, uma vez que, em apenas quatro aulas, foi possível fazer que os alunos compreendessem um conteúdo no qual estavam tendo muita dificuldade. Antes da aplicação da atividade, o professor, responsável pela disciplina de Química orgânica da turma tinha aplicado a avaliação bimestral com esse conteúdo e grande parte da sala obteve notas abaixo da média. Após a aplicação do jogo, os alunos comentavam entre si que se a avaliação fosse aplicada depois da atividade eles não teriam ficado com notas insuficientes.

O número de alunos com média acima de 8 triplicou após a utilização do jogo e dos com média acima de 9 quase dobrou a quantidade. Não se pode deixar de relatar que o número de alunos com nota abaixo de 6, na segunda prova, passou de 10 para 4, isto é, houve uma diminuição de mais de $50 \%$.

Além da melhoria do desempenho dos alunos na avaliação devido à atividade aplicada, alguns alunos fizeram relatos na segunda prova falando do jogo, como podemos observar nas Figuras 10, 11 e 12.

Figura 10- Depoimento de aluno na avaliação

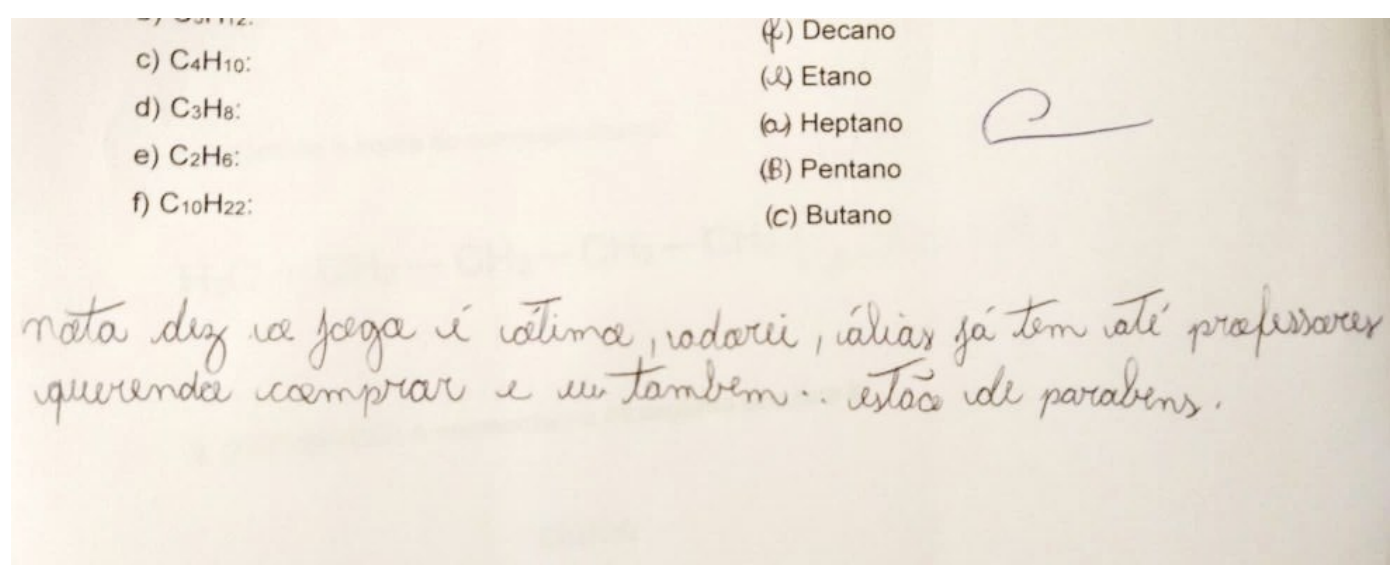

Fonte: Autoria própria (2017). 


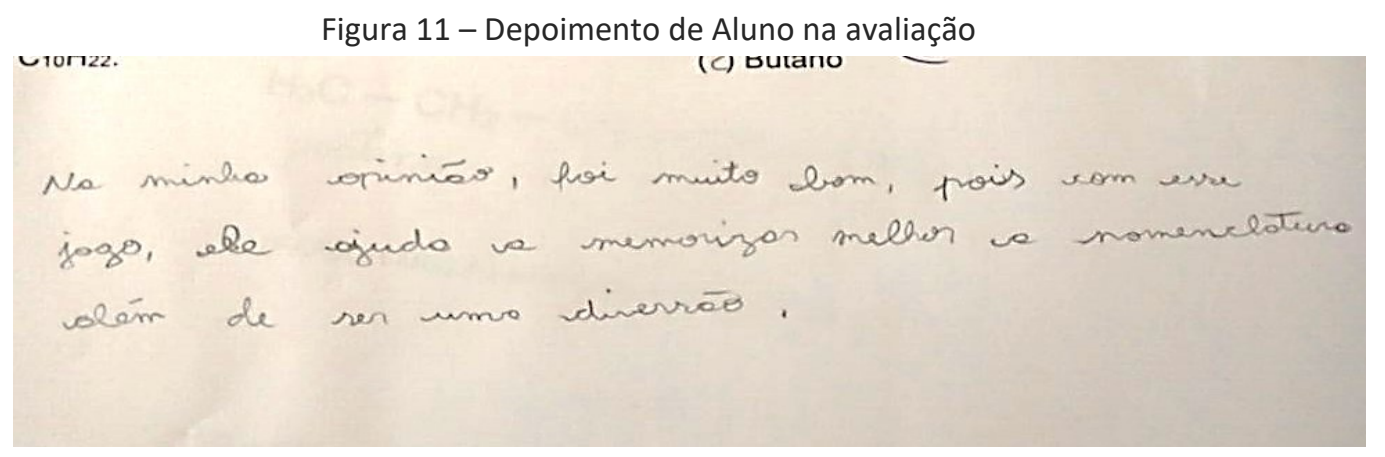

Fonte: Autoria própria (2017).

Figura 12 - Depoimento de aluno na avaliação

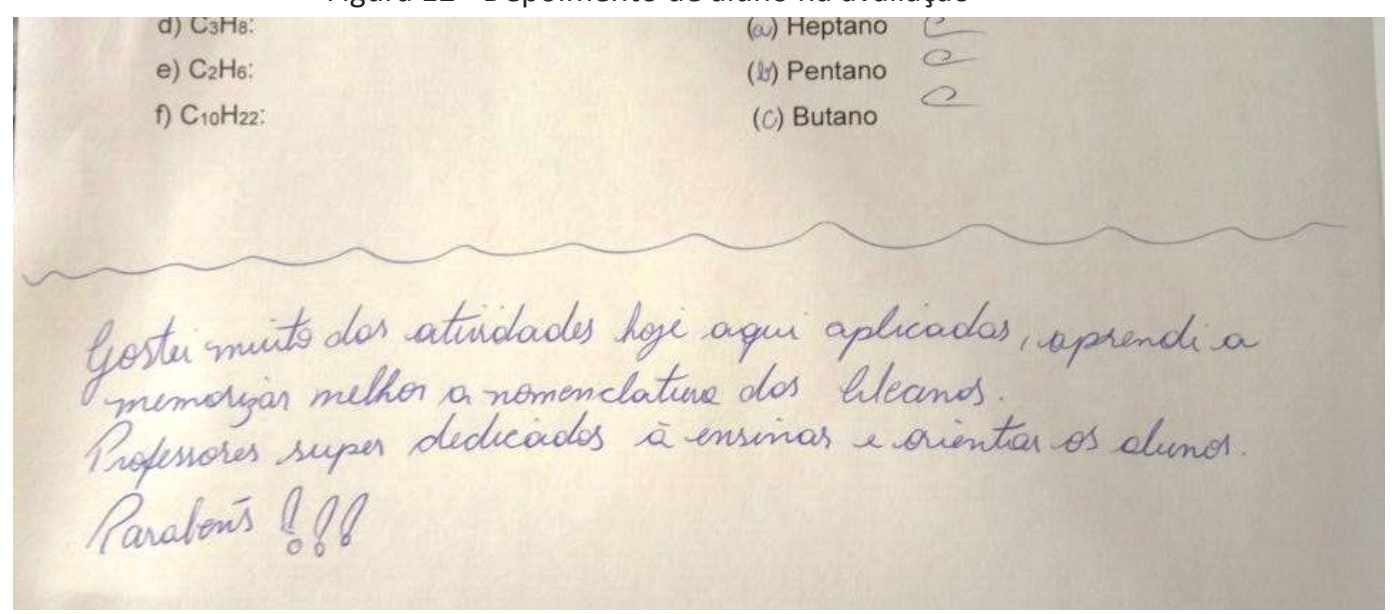

Fonte: Autoria própria (2017).

\section{DIFICULDADES ENCONTRADAS}

Para que os resultados fossem atingidos muitas dificuldades tiveram que ser superadas. Primeiramente uma delas foi a disponibilidade dos próprios autores para a aplicação do jogo, uma vez que cada um residia em uma cidade diferente. Em segundo lugar, houve a dificuldade de encontrar uma escola que estivesse disposta a aplicar a proposta, por conta de ter apenas duas horas-aulas de Química por semana, tempo não suficiente para realizar a aplicação das duas atividades avaliativas e o jogo de uma maneira mais clara e bem explicativa.

A média de idade dos alunos que realizaram o teste avaliativo deixa claro que a maioria dos alunos tinha acima dos 20 anos de idade. Em função disso, muitos deles não tinham contato com a Química escolar há algum tempo e, por isso, apresentavam dificuldades de baixo aprendizado do conteúdo. Esse fato já pôde ser observado durante a revisão do conteúdo, antes da aplicação da primeira prova, pois foi possível observar grande dificuldade no aprendizado dos alunos.

Por conta do curto tempo para a aplicação, foi realizado um acordo com os professores e com a direção do colégio para que tudo acontecesse de uma maneira satisfatória e sem prejudicar os horários das aulas. Ao bater o sinal (identificando que era o fim da segunda aula), os alunos mostravam-se surpresos, pois para eles o tempo havia passado muito rápido, demonstrando que o uso de atividades lúdicas contribui para a concentração do aluno durante a aula. As aulas expositivas 
os deixam entediados e isso, de alguma forma, acaba prejudicando o ensinoaprendizagem. Com a dinâmica do lúdico, todos alunos se sentiram mais à vontade e aprenderam brincando, sem se apegarem ao passar do tempo.

\section{CONSIDERAÇÕES FINAIS}

O jogo Dominó de Alcanos foi elaborado com o intuito de promover e facilitar a compreensão do conteúdo aplicado pelo professor. O jogo Dominó de Alcanos é relativamente muito simples de se jogar, com regras que se assemelham muito com o famoso "Dominó" encontrado em lojas de jogos de mesa, além de ser muito descontraído, competitivo, motivador e para a maioria da turma aplicada inovador. É interessante salientar que o uso dessa metodologia não é algo novo, porém apresenta uso bem restrito pela maioria dos educadores, o que torna o ensino muitas vezes cansativo e repetitivo. Com o uso da ferramenta lúdica o aluno se sente motivado e desafiado a atingir os objetivos propostos, fazendo com que ele tenha uma visão diferenciada da disciplina de Química, frente ao ensino tradicional. Como observado, a aplicação dessa atividade lúdica facilitou o aprendizado dos alunos, havendo melhoria na média do resultado avaliativo em $29 \%$, sendo a média da avaliação inicial de 5,5 e avaliação após a aplicação do jogo com média de 7,1. Pode-se concluir que, por meio da execução desse jogo em sala de aula, e após análise dos resultados obtidos a partir do mesmo, houve significativa melhoria na compreensão do conteúdo abordado. Além disso esse trabalho indicou que a prática de uma metodologia diferenciada como esta deve ser muito bem planejada pelo professor, cujo principal objetivo é educar, tornar o ensino de Química mais atraente, sendo as atividades lúdicas uma importante ferramenta para isso. 


\title{
Use of the ludic by dominoes for the learning of alkanes by Chemistry Technical Course students
}

\begin{abstract}
Games are traditional and present in human life for a long time, increasing the concentration and motivating who is playing. On this way, it arises the idea of using games for teaching school content. In Chemistry, it is not different, as there is the need of holding student's attention and stimulating them to keep learning on a great environment. The alkane nomenclature is a fundamental content for the comprehension of the organic functions, such as: aldehydes, carboxylic acids, ketones, esters, etc. Our goal on this study is analysing the domino use in the learning of alkanes nomenclature. This game was developed and applied on the first year class of a Chemistry Technical Course in the city of Paranavaí, Paraná. The experiment consisted on a review class about the hydrocarbons content, which had the application of a diagnostic test, consisted by 5 questions to be solved in 20 minutes or less using the domino and subsequent application of a new test. The students' performance was evaluated after rating scores from 0 to 10 and comparing them. The results indicate that the Alkanes Domino game facilitated the students' learning, achieving an improvement of $29 \%$ on the tests average score, having an initial score of 5.5 and final score of 7.1. It is concluded that the Alkanes Domino game is an important tool for improving students' learning, being simple to play and motivating. The idea of the game can be expanded to other contents.
\end{abstract}

KEYWORDS: Ludic education. Domino. Chemistry. Education. Chemistry Teaching. 


\section{AGRADECIMENTOS}

À direção do Colégio Enira de Moraes Ribeiro, que abriu as portas para execução do presente projeto, ao qual foi muito receptiva e interessada na metodologia proposta. Os resultados obtidos aconteceram graças à disponibilidade de atendimento que o colégio nos ofereceu, acreditando na ideia no projeto e se disponibilizando a ajudar sem medir esforços. E juntamente ao colégio, nossos agradecimentos também ao professor Diego Marlon, que ministra aulas de Química no curso técnico em Química e disponibilizou suas aulas, para que pudéssemos aplicar as provas e o jogo para seus alunos. Ao Instituto Federal do Paraná. 


\section{REFERÊNCIAS}

ARCE, A. A pedagogia na "Era das Revoluções": uma análise do pensamento de Pestalozzi e Froebel. São Paulo: Autores Associados, 2001.

BRASIL. Ministério da Educação. Parâmetros Curriculares Nacionais (PCN). Brasília: MEC, 1999.

CUNHA, M.B. Jogos no ensino de Química: considerações teóricas para sua utilização em sala de aula. Revista Química Nova na Escola, n. 2, v. 34, p. 92-98, 2012.

KISHIMOTO, T.M. O jogo e a educação infantil. São Paulo: Pioneira, 1996.

MELO, C.M.R. As atividades lúdicas são fundamentais para subsidiar ao processo de construção do conhecimento. Información Filosófica, v.2, n.1, p.128- 137, 2005.

POWELL, W.H; FRAVE, H.A. Nomenclature of Organic Chemistry: IUPAC Recommendations and Preferred Names, 2013.

SOARES, M.H.F.B. O lúdico em Química: Jogos e atividades lúdicas aplicados ao Ensino de Química. 2004. 203f. Tese (Doutorado em Ciências) - Universidade Federal de São Carlos, São Carlos, 2004.

SOARES, M. Jogos para o Ensino de Química: teoria, métodos e aplicações. Guarapari: ExLibris, 2008. 169 p..

Recebido: 29 mai. 2017

Aprovado: 21 ago. 2017

DOI: 10.3895/actio.v2n1.6778

Como citar:

SILVA, E. F.; SOUSA, G. L. dos S.; NEVES JUNIOR, W.; TESTA, G, PIMENTEL, T. C. Utilização do lúdico por meio de dominó para a aprendizagem de alcanos por alunos de Curso Técnico em Química. ACTIO,

Curitiba, v. 2, n. 1, p. 342-358, jan./jul. 2017. Disponível em: <https://periodicos.utfpr.edu.br/actio>. Acesso em: $X X X$.

Correspondência:

Tatiana Colombo Pimentel

Rua José Felipe Tequinha, 1400, Paranavaí, Paraná, Brasil.

Direito autoral: Este artigo está licenciado sob os termos da Licença CreativeCommons-Atribuição 4.0

Internacional.

(c) (i) 